\title{
A PERCEPÇÃO DOS GESTORES SOBRE AS DIMENSÕES DA SUSTENTABILIDADE
}

\author{
THE MANAGERS PERCEPTION ABOUT THE DIMENSIONS \\ OF SUSTAINABILITY
}

\author{
Claudia Veber ${ }^{1}$, Leticia LengleR ${ }^{2}$, Jefferson Menezes de Oliveira ${ }^{3}$, \\ Vania de Fátima Barros Estivalete ${ }^{4}$ e Jordana Marques Kneipp ${ }^{5}$
}

Recebido em: 10/07/2016

Aprovado em: 09/01/2017

\section{RESUMO}

Com a finalidade de discutir como uma organização trata a temática da sustentabilidade nas suas ações rotineiras, propôs-se a realização deste estudo de caso. O objetivo consiste em analisar a percepção dos gestores de uma Cooperativa de Assistência à Saúde sobre a sustentabilidade, já que a cooperativa em questão está começando a inserir a visão sustentável na sua prática de gestão. Já os objetivos específicos são: levantar as práticas relacionadas às dimensões econômica, social e ambiental da empresa; analisar as dimensões da sustentabilidade em que a empresa mais se destaca; e sugerir ações estratégicas para as dimensões que necessitam ser ainda mais desenvolvidas pela empresa. Após aplicar um questionário aos 23 gestores que compõem a diretoria da cooperativa estudada, identificou-se que a dimensão social é a que representa a maior dificuldade para que os gestores desenvolvam ações específicas voltadas para a gestão sustentável. Assim, sugere-se que a cooperativa busque e disponibilize mais informações sobre as condições de bem-estar dos cooperados, gestores, colaboradores e usuários por meio de campanhas, cursos, reuniões e palestras, tendo em vista que, assim, o impacto social poderia ser percebido de forma mais clara tanto pelos gestores quanto pelos demais colaboradores.

Palavras-chave: Sustentabilidade; percepção dos gestores, práticas de gestão.

\begin{abstract}
Aiming to discuss how a company handles the sustainability theme in its routine actions, this study case was proposed with the goal of analyzing the Health Assistance Cooperative managers' perceptions about sustainability, since the company has been inserting a sustainable vision in its management practice. As the secondary objectives, it was established: to raise practices related to the economic, social and environmental dimensions; to analyze the dimensions in which the company is most engaged; and to suggest strategic actions to the dimensions that need to be more developed by the company. After applying a questionnaire to the 23 managers of the cooperative, the social dimension was identified as the one with the highest degree of difficulty to the managers develop practical actions in terms of sustainable management. Therefore, it was suggested to the board to enrich and make available more information about cooperates, managers, collaborators and users well-being that is linked to the social dimensions activities performed by the cooperative, throughout campaigns, courses, meetings and lectures, focusing that the social impact of the company could be perceived and realized by the managers and collaborators in a clearer way.
\end{abstract}

Keywords: Sustainability, managers' perception, management practices.

\footnotetext{
1 Graduada em Administração pelo Centro Universitário Franciscano - UNIFRA. E-mail: claudiaveber@hotmail.com.br 2 Doutoranda em Administração - PPGA/UFSM. E-mail: llenglerworld@yahoo.com

3 Doutorando em Administração - PPGA/UFSM. E-mail: jeffersonmenezes@gmail.com

4 Doutora em Agronegócios pelo Programa de Pós-Graduação em Agronegócios da Universidade Federal do Rio Grande do Sul - UFRGS. Professora do Departamento de Ciências Administrativos da Universidade Federal de Santa Maria - UFSM. E-mail: vaniaestivalete@ufsm.br

5 Possui doutorado em Administração pela Universidade Federal de Santa Maria (2016). Atualmente é professora na Unidade Descentralizada de Educação Superior da UFSM em Silveira Martins - UDESSM. E-mail: jordanakneipp@yahoo.com.br
} 


\section{Introdução}

A preocupação com práticas sustentáveis tem influenciado a expansão dos negócios e a produtividade das organizações. Nesse sentido, a nova sociedade passa a exigir das empresas a prática da transparência no seu processo de governança e na distribuição de riqueza, obrigando-as a mostrar o que estão realmente devolvendo à sociedade e quais são os recursos que estão sendo utilizados.

Segundo Aligleri et al. (2010), o mundo tem ingressado na era da responsabilidade, em que as empresas podem e devem ser responsabilizadas não somente pelas ações realizadas, mas também pelos resultados e pelas consequências dessas ações. Para esses mesmos autores, a questão ambiental deixou de ser uma função exclusiva de produção para tornar-se uma função de administração. Ela está vinculada à estrutura organizacional, interferindo no planejamento estratégico e sendo considerada importante tanto no desenvolvimento das atividades rotineiras da empresa quanto na geração de políticas, metas e planos de ação. Assim, a preocupação com o meio ambiente torna-se um valor da empresa, sendo um dos objetivos principais a ser perseguido pelas organizações (ALIGLERI et al., 2010).

Essas preocupações têm conduzido a proposição de um modelo de desenvolvimento alicerçado na perspectiva da sustentabilidade (MADRUGA, 2011). Nesse modelo, Madruga (2011) explica que a dimensão econômica da sustentabilidade se soma às dimensões sociais e ambientais e que se processam reflexões sobre o bem-estar vigente, procurandose alternativas sustentáveis para o futuro, de modo atender as necessidades da sociedade no que diz respeito às questões ambientais e à qualidade de vida.

Inserido nesse contexto, o desenvolvimento do presente estudo orientou-se pela seguinte questão central de pesquisa: como a sustentabilidade é percebida pelos gestores de uma Coo- perativa de Assistência à Saúde do Brasil? Visando responder à problemática, a presente pesquisa tem como objetivo geral analisar a percepção dos gestores da cooperativa pesquisada em relação à sustentabilidade. Com o intuito de atingir esse objetivo, foram delineados os seguintes objetivos específicos: investigar a percepção dos gestores sobre as práticas relacionadas às dimensões econômica, social e ambiental da sustentabilidade; analisar as dimensões econômica, social e ambiental da sustentabilidade em que a empresa mais se destaca; e sugerir ações estratégicas com o intuito de potencializar as dimensões da sustentabilidade que necessitam ser mais desenvolvidas pela Cooperativa de Assistência à Saúde analisada.

A realização deste estudo se justifica tendo em vista que permitirá identificar a visão dos gestores em relação à sustentabilidade, possibilitando uma revisão de suas práticas e de seus conceitos relacionados ao tema no momento da tomada de decisões. A tomada de decisões embasadas na gestão sustentável tem grande importância para o mundo profissional, tendo em vista o crescimento da competitividade nesse mercado, que requer a construção de práticas operacionais sólidas e sustentáveis ao longo do tempo. Para que isso ocorra, torna-se necessário uma atitude de maior responsabilidade e transparência, com equilíbrio econômico, social e ambiental como forma de construção e de contribuição para o bem-estar e a qualidade de vida da comunidade, ao incorporar a sustentabilidade no negócio.

Diante do exposto, este artigo está estruturado em cinco seções, incluindo a introdução. A segunda seção apresenta a base teórica sobre sustentabilidade e suas principais dimensões. $\mathrm{Na}$ terceira seção, aborda-se o percurso metodológico utilizado para operacionalização do estudo. Na quarta seção, apresenta-se a análise e discussão dos resultados e, por fim, na quinta seção, são discutidas as considerações finais. 


\section{Fundamentação teórica}

A presente seção é dedicada à apresentação teórico-conceitual sobre a temática estudada, tendo suporte na apresentação de conceitos sobre a sustentabilidade, suas dimensões e implicações nas organizações.

\subsection{Sustentabilidade e organizações}

$\mathrm{O}$ entendimento de que as organizações consomem deliberadamente e cotidianamente os recursos ambientais e sociais do mundo, frequentemente de forma desregrada, desigual e prejudicial, tem conduzido muitas organizações a repensarem seus processos produtivos. Com base nesse entendimento, estudiosos e consultores empresariais visualizam a necessidade de melhor compreender quais mudanças seriam necessárias aos modelos de gestão para atender e englobar as premissas da sustentabilidade (MUNCK et al., 2016).

$\mathrm{O}$ conceito de sustentabilidade e as discussões relacionadas ao desenvolvimento sustentável são cada vez mais recorrentes em diferentes contextos e áreas do conhecimento. Em virtude dos inúmeros problemas sociais e ambientais que estão ocorrendo nas últimas décadas, são crescentes as preocupações sobre como atingir o desenvolvimento sustentável, definido como aquele "capaz de suprir as necessidades da geração atual, sem comprometer com a capacidade de atender as necessidades das futuras gerações" (WCED, 1987, p. 9).

De acordo com Leff (2001), o discurso da sustentabilidade busca reconciliar o meio ambiente e o crescimento econômico, com o objetivo de proclamar o crescimento econômico como um processo sustentável, estabelecido nos mecanismos do livre mercado como meio eficaz de garantir o equilíbrio ecológico e a igualdade social. Para Claro, Claro e Amâncio (2008), muitas empresas têm problemas em integrar o discurso e a prática empresarial em termos de susten- tabilidade, pois algumas empresas focam em questões sociais, outras em questões ambientais e várias vislumbram somente as questões econômicas.

Uma pesquisa feita em 14 países no ano de 2011 pelo grupo francês de comunicação Havas revela que, dentre mais de 4.000 consumidores brasileiros entrevistados, $60 \%$ acreditam que a maioria das empresas se mostra responsável apenas para melhorar sua imagem, e $26 \%$ avaliam que as companhias comunicam suas reais iniciativas ambientais $\mathrm{e}$ sociais (BRITO, 2011). Além disso, $85 \%$ das entrevistadas afirmaram que estão incluindo no seu planejamento estratégico, além de ações ambientais, medidas para reduzir a pobreza e aumentar a inclusão perante a sociedade (BRITO, 2011).

A sustentabilidade ganhou ímpeto com a eclosão do que denominamos temas emergentes, como ecologia, meio ambiente, voluntariado, educação, saúde, bem-estar, combate à fome e à pobreza, exclusão social e direitos humanos (MELO NETO; BRENNAND, 2004). Sendo assim, as empresas estão se vendo obrigadas a repensar suas estratégias e integrar as variáveis referentes à sustentabilidade nas suas decisões de planejamento, implementação e controle, a fim de buscar um diferencial para seus produtos e/ou serviços e ampliar a sua participação de mercado.

Essas mudanças afetam de forma intensa o ambiente social e político em que a organização atua, criando novas diretrizes e limitações para que ela possa operar de forma eficaz, segundo uma ótica que não leve em conta apenas a maximização do retorno financeiro (MAIMON, 1996).

\subsection{Dimensões da sustentabilidade}

Para Almeida (2007), além de estabelecer o equilíbrio entre objetivos econômicos, sociais e ambientais, a sustentabilidade potencializa o compartilhamento de poder entre governos, empresas e organizações da sociedade 
civil. Na visão do autor, a melhor compreensão desses três fatores proporcionará a redução dos impactos prejudiciais à sociedade, como, por exemplo, no que diz respeito às concessões ambientais, instrumentos fundamentais para consolidar o desenvolvimento sustentável, mas que ainda continuam atrelados ao modelo ultrapassado de comando e controle.

Embora a preocupação com a sustentabilidade esteja ainda muito ligada às questões ambientais, Sachs (2002) aponta que a sustentabilidade é fundamentada no tripé social-econômico-ambiental (Figura 1), que deve considerar o impacto das três dimensões de forma igualitária.

Figura 1: Tripé da sustentabilidade

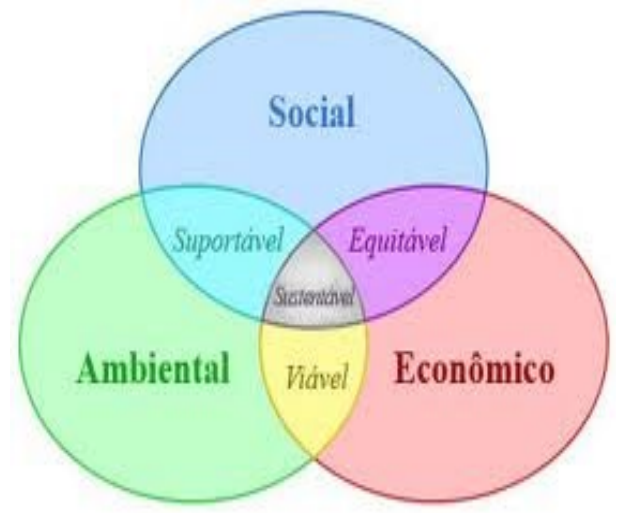

Fonte: Sachs (2002).

A teoria do desenvolvimento sustentável sugere uma visão tridimensional desse desenvolvimento, em que a eficiência econômica se interliga à dimensão ecológica e à ideia da realização de uma sociedade solidária e justa. É esse tripé que engloba a dimensão econômica, dimensão social e dimensão ambiental (SACHS, 2002). De acordo com Fenker (2012), essa evolução do conceito de sustentabilidade, apoiada no Triple Bottom Line, envolve as diferentes dimensões - econômica, social e ambiental - de tal forma que se obtenha a otimização sistêmica na organização.

Além das oposições entre o crescimento econômico, a conservação ecológica e a preservação do ambiente, ori- ginam-se novas economias sustentáveis, baseadas no potencial produtivo dos sistemas ecológicos, nos valores culturais e em uma gestão participativa das comunidades locais (LEFF, 2001). A partir daí, surge o desafio de criar estratégias que permitam unir as economias locais com a economia de mercado, de forma a preservar a autonomia cultural e as condições ecológicas para o desenvolvimento sustentável de cada comunidade.

O consumidor, cada vez mais consciente, começa a refletir e busca fazer melhores escolhas levando em conta não apenas o aspecto econômico viável, mas também o ambientalmente correto e socialmente justo (SOUSA, 2011). Não fosse essa nova preocupação do consumidor, as empresas estariam preocupadas somente com o resultado econômico de suas atividades. Afinal, não apenas as pessoas precisam mudar, como também as organizações perceberam que, se pretendem permanecer no mercado por mais de 20 anos, precisam adotar novas práticas sustentáveis para o seu pleno desenvolvimento.

Na visão de Donaire (1999), as novas oportunidades criadas a partir da preocupação com a questão ambiental proporcionam às empresas que aderirem a esse novo pensamento vantagens competitivas e maior reconhecimento entre os clientes. São inúmeros os benefícios tanto econômicos quanto estratégicos que a variável ambiental pode trazer às organizações, tais como: redução do consumo de água, energia e outros insumos; economia devido à reciclagem e ao aproveitamento de resíduos; aumento da participação no mercado devido à inovação de produtos e à menor concorrência; melhoria da imagem institucional; melhoria nas relações de trabalho; e melhor adequação aos padrões ambientais.

De acordo com Tachizawa (2004), incluir a proteção ao meio ambiente entre os objetivos estratégicos da organização amplia todo o conceito de administração. Diversas práticas como 
programas de reciclagem, medidas para poupar energia e demais inovações ecológicas resultarão, em breve, em novos sistemas de administração de cunho ecológico. Esse novo pensamento deve ser acompanhado de uma mudança de valores, passando da quantidade para a qualidade. "O novo pensamento e o novo sistema de valores, juntamente com as correspondentes percepções e novas práticas, constituem o que se dominam de 'novo paradigma', com reflexos imediatos nas escolas de formação e preparação de administradores" (TACHIZAWA, 2004, p. 27).

Já a dimensão social envolve desde a redução de custos sociais até a responsabilidade de contribuir para o desenvolvimento econômico e a melhoria das condições sociais (DONAIRE, 1999). Essa responsabilidade social está relacionada a um conceito ético que envolve mudanças nas condições de bem-estar, nas dimensões sociais das atividades produtivas e na qualidade de vida na sociedade. Portanto, trata-se da relação entre a empresa e o seu ambiente de negócios.

O "negócio sustentável e responsável" é entendido aqui como a atividade econômica orientada para a geração de valor econômico-financeiro, ético, social e ambiental, cujos resultados são compartilhados com os públicos afetados e cuja produção e comercialização são organizadas de modo a reduzir continuamente o consumo de bens naturais e serviços ecossistêmicos, visando a dar competitividade e continuidade à própria atividade e a manter o desenvolvimento sustentável da sociedade civilizatório atual (ITACARAMBI, 2013).

Para Jorge Abrahão, presidente do Instituto Ethos de Empresas e Responsabilidade Social, muitas organizações investem em iniciativas sustentáveis apenas preocupadas com a visibilidade de seus negócios, e não com as reais consequências que suas ações podem gerar (BACARJI, 2011). No entanto, não é exagero afirmar que os indicadores de responsabilidade social ajudaram a estabelecer uma agenda de mudanças nos negócios no que diz respeito à ética e aos impactos socioambientais. Eles também contribuíram para estabelecer o comportamento socialmente responsável como um padrão para se pensar a sustentabilidade nos negócios.

\section{Procedimentos metodológicos}

O presente estudo é de natureza quantitativa e qualitativa. Para Richardson (1999, p. 70), uma pesquisa de natureza quantitativa caracteriza-se pelo emprego de quantificação das modalidades de coleta e tratamento de informação por meio de técnicas estatísticas.

Já na pesquisa qualitativa, segundo Triviños (1987), realizam-se a escolha de um assunto ou problema, bem como a coleta e análise de informações, sendo indispensável, nesse tipo de pesquisa, fazer esclarecimentos relevantes sobre o tema. Nesse modelo de pesquisa, ao contrário da quantitativa, não será exigido definir variáveis e medi-las, mas apenas descrevê-las.

Esta pesquisa é de caráter descritivo, pois, conforme Malhotra (2012), descreve as características e percepções em relação a determinado fato ou objeto, bem como determina em que grau estão associadas às variáveis em estudo. Nesse sentido, primeiramente, explorou-se o que Cooperativa de Assistência à Saúde pesquisada desenvolve em relação à gestão sustentável, para, a partir disso, descrever cada ação referente às esferas da sustentabilidade e as possíveis deficiências identificadas.

Em relação à estratégia de pesquisa, este estudo se caracteriza como um estudo de caso realizado em uma Cooperativa de Assistência à Saúde. Vergara (2004) concebe esse tipo de pesquisa como aquela que é realizada em áreas em que há pouco conhecimento acumulado e sistematizado.

A cooperativa pesquisada faz parte da maior rede de assistência médica do Brasil, que, atualmente, está presen- 
te em $83 \%$ do território nacional. Ela foi fundada em 1972 por um grupo de 75 médicos de um município do interior do Rio Grande do Sul. Atualmente, a cooperativa atende mais de 111 mil clientes, possui 761 médicos cooperados em 50 especialidades e mantém convênios com laboratórios, centros de radiologia e diversos hospitais da região. Dispõe de um sistema de medicina preventiva, atendimento domiciliar, medicina do trabalho, pronto atendimento, SOS e um hospital próprio. A cooperativa conta, na atualidade, com mais de 400 colaboradores entre profissionais administrativos e da área da saúde. Ela é administrada por um Conselho de Administração, composto de nove membros escolhidos por meio de votação realizada em Assembleia Geral, com todos os cooperados - destes nove membros, três são escolhidos para ocupar os cargos de Presidente, Vice-presidente e Super Intendente. Também fazem parte da diretoria cinco membros pertencentes ao Conselho Fiscal. Além desses diretores, há, na administração da cooperativa, uma Gerência Administrativa, composta de nove membros, que responde por sua administração, seu planejamento e seu controle, sendo a responsável geral por todos os departamentos da cooperativa e respondendo e assinando em conjunto com a Direção Executiva. Assim, esses 23 gestores são os responsáveis pelos demais profissionais que atuam nos 21 setores da cooperativa: departamento financeiro, contabilidade, recursos humanos, contas médicas, cadastro, faturamento, comercial, controladoria, aquisições, contratos, Tecnologia da Informação, departamento pessoal, intercâmbio, medicina preventiva, atendimento domiciliar, SOS, medicina do trabalho, enfermagem, regional, administrativo e hospital.

Como plano de coleta de dados, utilizou-se, primeiramente, de pesquisa bibliográfica, que, segundo Gil (2002, p. 44), "é desenvolvida com base em material já elaborado, constituído princi- palmente de livros e artigos científicos". Para tanto, recorreu-se ao estudo em livros, revistas e artigos, além do uso da internet, com o propósito de trazer ao presente estudo conceitos, contextualizações e ponderações dos mais variados autores em relação aos temas abordados.

Posteriormente, utilizaram-se entrevistas informais com alguns gestores, a fim de verificar sua percepção quanto às ações de sustentabilidade desenvolvidas no âmbito interno da cooperativa, adotando-se como base as práticas já desenvolvidas pela cooperativa. Destaca-se que a técnica de observação direta na rotina organizacional da cooperativa também foi empregada, tendo em vista que uma das pesquisadoras era funcionária da cooperativa quando ocorreu a pesquisa. A coleta de dados, por meio da técnica de observação, busca conseguir informações, utilizando os sentidos para compreender certos aspectos da realidade que são, à primeira vista, incompreensíveis. A observação desempenha papel importante, pois obriga o investigador a estabelecer um contato direto com a realidade estudada (MARCONI; LAKATOS, 2002). Por meio dessa técnica, objetivou-se captar os aspectos descritivos e analíticos, para perceber a consistência ou não entre o discurso e a prática dos sujeitos mediante a possibilidade de obter dados adicionais para a complementação das informações.

$\mathrm{Na}$ sequência, foram aplicados questionários junto a 23 gestores da cooperativa analisada. $\mathrm{O}$ instrumento de coleta foi elaborado pela pesquisadora alicerçado no referencial teórico que trata da temática estudada. O questionário compreende 29 perguntas fechadas, sendo quatro sobre o perfil dos pesquisados, nove sobre a esfera econômica, nove sobre a esfera social e sete sobre a esfera ambiental. Utilizou-se a escala do tipo Likert ${ }^{6}$ de cinco pontos, variando de nunca (1), quase nunca (2), às vezes

\footnotetext{
6 Escala Likert é um tipo de escala de resposta psicométrica usada habitualmente em questionários, sobretudo em pesquisas de opinião. Ao responderem a um questionário baseado nessa escala, os perguntados especificam seu nível de concordância com uma afirmação. Essa escala tem seu nome derivado da publicação de um relatório que explica seu
} uso e que foi escrito por Rensis Likert(CUMMINS e GULLONE, 2000). 
(3), quase sempre (4) à sempre (5), para identificar a frequência com que os gestores percebem os aspectos econômicos, sociais e ambientais na rotina da cooperativa. Destaca-se que foi usado um arredondamento para as médias, seguindo o critério de empregar apenas números inteiros. Para tanto, médias como, por exemplo, 3,49 foram indicadas como média 3,0 e médias como, por exemplo, 3,51 foram indicadas como média 4,0, de modo a facilitar a análise dos resultados.

No plano de análise de dados, primeiramente os dados foram tabulados com o auxílio do software SPSS 14.0 e posteriormente analisados sob a ótica quantitativa (frequência, porcentagens e médias) e qualitativa (com relação às práticas implementadas nas atividades diárias da cooperativa, que foram percebidas com a observação in loco e posteriormente discutidas).

\section{Análise dos resultados}

A apresentação dos dados dividese em duas etapas. Na primeira, apresenta-se uma descrição detalhada sobre o perfil dos pesquisados e, na segunda, verifica-se a percepção dos gestores em relação à sustentabilidade no âmbito interno da cooperativa, observando-se as esferas econômicas, social e ambiental.

\subsection{Perfil dos pesquisados}

Quanto ao sexo, conforme se observa na Tabela 1 , dos 23 supervisores pesquisados, 17 são do sexo feminino, e seis são do sexo masculino.

Tabela 1: Sexo

\begin{tabular}{ccc}
\hline & Frequência & Percentual \\
\hline Masculino & 6 & 26,0 \\
Feminino & 17 & 74,0 \\
Total & 23 & 100,0 \\
\hline
\end{tabular}

Como a Tabela 1 demonstra, $74 \%$ dos pesquisados são do sexo feminino, e apenas são $26 \%$ do sexo masculino. De acordo a Organização das Nações Unidas (ONU, 2011) e com os dados da Relação Anual de Informações Sociais (RAIS) do Ministério do Trabalho e Emprego (MTE), a participação da mulher no mercado de trabalho tem sido crescente nos últimos anos. Os registros da RAIS (2012) revelam que o nível de emprego com carteira assinada para as mulheres cresceu 5,93\% em 2012 em relação ao ano anterior e que isso continua sendo recorrente.

Na Tabela 2, observa-se a idade dos participantes da pesquisa.

Tabela 2: Faixa etária

\begin{tabular}{ccc}
\hline & Frequência & Percentual \\
\hline menos de 29 & 4 & 17,4 \\
de 30 a 39 anos & 4 & 17,4 \\
de 40 a 49 anos & $\mathbf{1 1}$ & $\mathbf{4 7 , 8}$ \\
de 50 a 59 anos & 3 & 13,1 \\
acima de 60 & 1 & 4,3 \\
anos & 23 & 100,0 \\
Total &
\end{tabular}

Observando a Tabela 2, constatase que todas as faixas etárias estão representadas, o que evidencia certa mudança cultural em relação ao passado, quando os cargos de chefia eram ocupados por pessoas com faixa etária superior a 40 anos. Apesar dessas mudanças culturais, no que diz respeito à faixa etária com maior número de gestores, observou-se que os mesmos possuem de 40 a 49 anos $(47,8 \%)$, o que demonstra que a cooperativa ainda é bastante tradicional com relação à cultura de gestão. As demais faixas são representadas por $17,4 \%$ cada uma, e apenas um gestor está na faixa dos 60 anos. Destaca-se uma média de idade de 40,91, com mínimo de 26 anos e máximo de 60 anos.

De acordo com a Tabela 3, que evidencia o tempo de atuação na cooperativa, compreende-se que os respondentes da faixa dos 40 anos são os que trabalham há mais tempo na coopera- 
tiva, de cinco a 15 anos, justificando o baixo nível de rotatividade e o desenvolvimento profissional dos respondentes. Observa-se na Tabela 2 que, dos 11 gestores que pertencem à faixa dos 40 anos, oito deles, ou seja, $72,7 \%$, estão enquadrados no período de tempo de cooperativa dos cinco aos 15 anos, conforme identificado na Tabela 3. Esses resultados podem ser um indicativo da existência de certa maturidade organizacional na cooperativa pesquisada.

Os dados apresentados na Tabela 3 permitem identificar o tempo há que os pesquisados atuam na cooperativa.

Tabela 3: Tempo de atuação dos gestores na cooperativa

\begin{tabular}{ccc}
\hline & Frequência & Percentual \\
\hline $\begin{array}{c}\text { Menos de 5 } \\
\text { anos }\end{array}$ & 3 & 13,1 \\
$\begin{array}{c}\text { De 5 a 15 } \\
\text { anos }\end{array}$ & $\mathbf{1 2}$ & $\mathbf{5 2 , 2}$ \\
$\begin{array}{c}\text { De 16 a 25 } \\
\text { anos }\end{array}$ & 7 & 30,4 \\
$\begin{array}{c}\text { Mais de 25 } \\
\text { anos }\end{array}$ & 1 & 4,3 \\
Total & 23 & 100,0 \\
\hline
\end{tabular}

Referente ao tempo na cooperativa, verificou-se que apenas um $(4,3 \%)$ dos gestores possui mais de 25 anos de atuação e que $13,1 \%$ possuem menos de cinco anos. A faixa de tempo de cinco a 15 anos foi a de maior percentual, $52,2 \%$. Pode-se inferir, com base nos dados apresentados, que a rotatividade não é um problema na cooperativa investigada. Mais da metade dos respondentes é constituída de pessoas com mais de cinco anos de vínculo funcional, o que pode indicar que esse perfil contribui para a cooperativa ter uma cultura forte, facilitando a implementação de estratégias, devido à sua maturidade, tendo em vista que a maioria dos supervisores apresenta idade superior a 40 anos (Tabela 2). Para Porter (1986), a maturidade funcional pode condicionar a longevidade da organização den- tro de um mercado.

A Tabela 4 apresenta o grau de instrução dos respondentes.

Tabela 04: Formação

\begin{tabular}{ccc}
\hline & Frequência & Percentual \\
\hline $\begin{array}{c}\text { Superior incom- } \\
\text { pleto }\end{array}$ & 1 & 4,3 \\
$\begin{array}{c}\text { Superior Com- } \\
\text { pleto }\end{array}$ & 2 & 8,7 \\
$\begin{array}{c}\text { MBA/Especia- } \\
\text { lização }\end{array}$ & $\mathbf{1 8}$ & $\mathbf{7 8 , 3}$ \\
Mestrado & 2 & 8,7 \\
Total & 23 & 100,0 \\
\hline
\end{tabular}

Com relação ao grau de instrução, identificou-se que a maioria dos gestores (78,3\%) possui Especialização/ MBA. Apenas um gestor $(4,3 \%)$ citou ter ensino superior em andamento. Os demais possuem percentual idêntico para mestrado $(8,7 \%)$ e ensino superior completo $(8,7 \%)$. Constata-se, assim, que a formação acadêmica é uma prática comum entre os gestores, fato que pode estar aliado à responsabilidade das exigências do cargo e até mesmo aos valores que a cooperativa preza. Além disso, das 17 mulheres (conforme Tabela 1 , que são a maioria nos cargos de chefia da cooperativa), 14 possuem MBA, e outras duas, mestrado. Esses dados revelam que as mulheres possuem um nível de qualificação elevado, o que demonstra a preocupação de estarem preparadas para enfrentar o mercado de trabalho. É notório que as mulheres vêm, cada vez mais, conquistando espaço no mercado de trabalho e melhorando seu salário, de modo a diminuir gradativamente uma diferença histórica, segundo dados do CAGED (2012).

4.2 Percepção dos gestores sobre a sustentabilidade

$\mathrm{Na}$ Tabela 5, procurou-se identificar os aspectos econômicos da sustentabilidade organizacional. 
Tabela 5 - Aspectos econômicos da sustentabilidade

\begin{tabular}{|c|c|c|c|c|}
\hline Questões & $\mathbf{N}$ & Média & Mínimo & Máximo \\
\hline $\begin{array}{l}\text { 1) A cooperativa procura implantar em seus processos a } \\
\text { prática de orientação da política de compras para priori- } \\
\text { zar fornecedores que não prejudiquem o meio ambiente? }\end{array}$ & 23 & 3,0 & 1 & 5 \\
\hline $\begin{array}{l}\text { 2) Para contratar um fornecedor, além de exigir uma boa pro- } \\
\text { posta comercial (com qualidade, preço e prazo), a cooperati- } \\
\text { va avalia se ele mantém práticas de responsabilidade social? }\end{array}$ & 23 & 2,0 & 1 & 5 \\
\hline $\begin{array}{l}\text { 3) A cooperativa pratica em suas dependências ações } \\
\text { para a redução do consumo de água (como instalação } \\
\text { de torneiras com fechamento automático e de descargas } \\
\text { com vazão reduzida ou aproveitamento da água da chu- } \\
\text { va para as atividades de limpeza e manutenção)? }\end{array}$ & 23 & 3,0 & 1 & 5 \\
\hline $\begin{array}{l}\text { 4) A cooperativa desenvolve ações de responsabilidade } \\
\text { social em parceria com os fornecedores? }\end{array}$ & 23 & 2,0 & 1 & 5 \\
\hline $\begin{array}{l}\text { 5) A cooperativa procura implementar em suas ativida- } \\
\text { des ações de economia do papel (como a utilização da } \\
\text { frente e do verso das folhas)? }\end{array}$ & 23 & 4,0 & 1 & 5 \\
\hline $\begin{array}{l}\text { 6) Em sua comunicação (contratos publicitários e mídia), } \\
\text { a cooperativa incentiva e educa seus consumidores a ado- } \\
\text { tar atitudes conscientes e responsáveis de consumo (como } \\
\text { o descarte adequado de embalagens, por exemplo)? }\end{array}$ & 23 & 3,0 & 1 & 5 \\
\hline $\begin{array}{l}\text { 7) Em suas promoções de marketing, a cooperativa divulga } \\
\text { suas práticas e ações como uma "Empresa Verde"? }\end{array}$ & 23 & 3,0 & 1 & 5 \\
\hline $\begin{array}{l}\text { 8) A cooperativa acredita que obteve e/ou obterá benefícios } \\
\text { para o negócio como resultado de sua atividade em ações } \\
\text { e práticas sustentáveis ? Por exemplo, passa a entender que } \\
\text { a "simpatia" da comunidade/mercado por suas iniciativas } \\
\text { resultará em um maior volume de vendas de seus serviços). }\end{array}$ & 23 & 3,0 & 1 & 5 \\
\hline $\begin{array}{l}\text { 9) A cooperativa destaca suas atividades de responsabili- } \\
\text { dade social em seu material promocional ou em seu site, } \\
\text { aproveitando para inserir no mercado a sua imagem verde? }\end{array}$ & 23 & 3,0 & 1 & 5 \\
\hline
\end{tabular}

Avaliando os resultados da Tabela 5, a maior média encontrada é a de 4,0 pontos para a questão 5 , em contrapartida às questões $2 \mathrm{e} 4$, que obtiveram a menor média (de 2,0 pontos cada). Observando as duas questões com menor percepção, verifica-se que ambas são relacionadas às negociações com fornecedores, o que pode ser um indicativo de que a cooperativa estudada, ao estabelecer as contratações de fornecedores, deve dar maior atenção às práticas de responsabilidade social, priorizando compras ecologicamente corretas. Os dados apresentados na Tabela 5 remetem ao entendimento de que a cooperativa, ao realizar suas compras, deve optar por fornecedores que possuam preocupações com o descarte correto das embalagens e que vendam produtos ecologicamente cor- retos. Dessa forma, estaria valorizando essas práticas e incentivando o comércio dos referidos itens.

Quanto à questão 5 - "A cooperativa procura implementar em suas atividades ações de economia do papel?" -, que obteve a média mais alta $(4,0)$, pode-se inferir que isso ocorre em função de uma das ações da cooperativa (em relação ao aspecto econômico) já estar em prática, isto é, a utilização da assinatura eletrônica ao final do e-mail, conforme evidenciado na Figura 2. Essa iniciativa é uma das formas utilizadas pela cooperativa que reflete a atenção para a real necessidade de que o e-mail seja impresso.

Cabe acrescentar que, embora alguns aspectos relacionados à dimensão econômica da sustentabilidade tenham 
Figura 2. Assinatura eletrônica dos colaboradores da cooperativa

apresentado médias mais altas, constatou-se que a média geral dessa dimensão é 2,88. Na Tabela 6, procurou-se verificar os aspectos sociais da sustentabilidade organizacional.

Conforme os dados apresentados na Tabela 6 , é possível verificar que a maior média encontrada é para a questão 15 , sendo avaliada pela maio- ria como "quase sempre". As demais questões referentes aos aspectos sociais oscilaram na escala "quase nunca" e "às vezes". Das nove questões referentes aos aspectos sociais, cinco $(55,55 \%)$ obtiveram média 2,0, o que demonstra maior dificuldade para que a cooperativa desenvolva ações na esfera social da sustentabilidade organizacional.

Tabela 06 - Aspectos sociais da sustentabilidade

\begin{tabular}{|c|c|c|c|c|}
\hline Questões & $\mathbf{N}$ & Média & Mínimo & Máximo \\
\hline $\begin{array}{l}\text { 10) A cooperativa possui documento formal que esclare- } \\
\text { ce quais são os parâmetros incentivados por ela no que } \\
\text { se refere às relações sustentáveis? }\end{array}$ & 23 & 2,0 & 1 & 5 \\
\hline $\begin{array}{l}\text { 11) A cooperativa procura envolver suas partes interessa- } \\
\text { das (colaboradores, clientes, fornecedores, comunidade e } \\
\text { diretoria) na elaboração e revisão desse documento? }\end{array}$ & 23 & 2,0 & 1 & 5 \\
\hline $\begin{array}{l}\text { 12) Você percebe que a cooperativa acredita que o Ba- } \\
\text { lanço Social pode ajudá-la a medir o impacto de suas } \\
\text { operações sobre o meio ambiente e a divulgar seus com- } \\
\text { promissos futuros em relação a esses temas? }\end{array}$ & 23 & 2,0 & 1 & 5 \\
\hline $\begin{array}{l}\text { 13) Além de cumprir as obrigações determinadas por } \\
\text { lei, a cooperativa se preocupa em oferecer a seus cola- } \\
\text { boradores um ambiente físico agradável e seguro? Por } \\
\text { exemplo: aboliu o fumo em local de trabalho? Incentiva } \\
\text { os colaboradores a praticarem atividades físicas? Orien- } \\
\text { ta os colaboradores quanto aos cuidados com a postura } \\
\text { corporal durante as atividades profissionais? }\end{array}$ & 23 & 3,0 & 2 & 5 \\
\hline $\begin{array}{l}\text { 14) As dependências da cooperativa contam com recursos } \\
\text { para facilitar o deslocamento e a convivência (disponibili- } \\
\text { za treinamento para os colaboradores se comunicarem com } \\
\text { outros colegas na linguagem de sinais, por exemplo) de } \\
\text { pessoas com deficiência motora, auditiva ou visual (como } \\
\text { rampas, avisos de segurança em braile, sinais luminosos e } \\
\text { sonoros em áreas de circulação de veículos etc.)? }\end{array}$ & 23 & 3,0 & 1 & 5 \\
\hline $\begin{array}{l}\text { 15) A cooperativa valoriza a diversidade, não utilizando } \\
\text { práticas discriminatórias em relação à gênero, à raça, à } \\
\text { orientação sexual, à idade e a crenças religiosas ou polí- } \\
\text { ticas dos candidatos, bem como a pessoas com deficiên- } \\
\text { cia na seleção de pessoal? }\end{array}$ & 23 & 4,0 & 2 & 5 \\
\hline $\begin{array}{l}\text { 16) A cooperativa considera importante e aplica ações para } \\
\text { fins de desenvolvimento da comunidade local por meio da } \\
\text { geração de trabalho e renda, bem como medidas para redu- } \\
\text { zir a pobreza e aumentar a inclusão perante a sociedade? }\end{array}$ & 23 & 2,0 & 1 & 5 \\
\hline
\end{tabular}


17) A cooperativa incentiva o trabalho voluntário de seus colaboradores na comunidade e reconhece a importância do trabalho voluntário de seus colaboradores, divulgando-o por meio de murais, jornal interno ou jornal local?

18) A responsabilidade social empresarial deve ser uma forma de gestão do negócio, e o lucro é parte do processo. Ao optar por ser uma "Empresa Verde", a cooperativa realiza na comunidade campanhas educacionais e/ou de interesse público em conjunto com organizações locais?

Dentre as cinco questões com menor grau de percepção, destaca-se a questão 12 , em que se questiona a importância do Balanço Social, pois 43,5\% dos gestores dizem que "nunca percebem" essa prática na cooperativa. Esses resultados merecem atenção por parte da cooperativa, uma vez que o Balanço Social ou a Contabilidade Ambiental, como também é denominado, é um conceito que evidencia a transparência e mensura os impactos ambientais dentro das organizações. Para Tinoco (2010, p. 13), "a contabilidade, além do registro de transações econômicas, passa a apresentar eventos ambientais, assumindo o papel de divulgação das ações de gestão ambiental, tendo em vista prevenir e corrigir danos, bem como salvaguardar os patrimônios empresarial e nacional". Essa imposição independe da entidade ser ou não ambientalmente íntegra. Uma das atividades no âmbito social realizada pela cooperativa foi a Oficina de Natal (cujo slogan consta na Figura 3), na qual os colaboradores aprenderam a confeccionar enfeites para o natal com material que havia sido descartado durante o ano. $\begin{array}{llll}23 & 3,0 & 1 & 5\end{array}$

5

(3)

$\begin{array}{llll}23,0 & 1 & 5\end{array}$

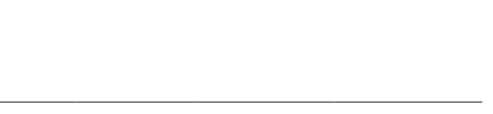

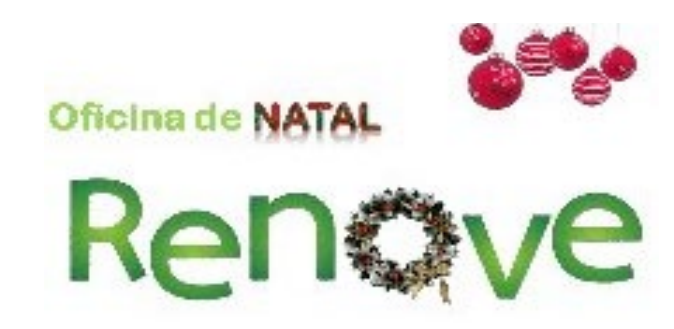

Figura 3. Cartaz da oficina de Natal

Assim, a dimensão social ainda parece ser pouco desenvolvida pela cooperativa, uma vez que a média geral dessa dimensão é 2,55. A Tabela 7, a seguir, busca evidenciar os aspectos ambientais da sustentabilidade organizacional. 
Tabela 07 - Aspectos ambientais da sustentabilidade

\begin{tabular}{|c|c|c|c|c|}
\hline Questões & $\mathbf{N}$ & Média & Mínimo & Máximo \\
\hline $\begin{array}{l}\text { 19) A cooperativa conhece, entende e avalia os impactos } \\
\text { de suas atividades sobre o meio ambiente (como emis- } \\
\text { são de poluentes e alto consumo de energia, de água e de } \\
\text { combustível), mantendo relatórios para medi-los? }\end{array}$ & 23 & 3,0 & 1 & 5 \\
\hline $\begin{array}{l}\text { 20) A cooperativa procura utilizar em seus processos } \\
\text { materiais que causem menos danos ao meio ambiente } \\
\text { ? Por exemplo: procura controlar e reduzir a poluição } \\
\text { sonora e visual, causadas por seus processos? }\end{array}$ & 23 & 3,0 & 2 & 5 \\
\hline $\begin{array}{l}\text { 21) A cooperativa discute parcerias com fornecedores, } \\
\text { visando ao retorno ao fabricante de materiais descarta- } \\
\text { dos (como produtos vencidos, pilhas, baterias, pneus } \\
\text { usados e lâmpadas usadas)? }\end{array}$ & 23 & 3,0 & 1 & 5 \\
\hline $\begin{array}{l}\text { 22) A cooperativa procura implementar em suas depen- } \\
\text { dências e em suas atividades ações que visam preservar } \\
\text { o meio ambiente (por exemplo: coleta seletiva de lixo, } \\
\text { com recipientes identificados para papel, vidro, metal, } \\
\text { plástico e material orgânico)? }\end{array}$ & 23 & 4,0 & 2 & 5 \\
\hline $\begin{array}{l}\text { 23) A cooperativa pratica em suas dependências ações } \\
\text { como destinação final adequada para resíduos que ne- } \\
\text { cessitam de tratamento específico, como pilhas, bate- } \\
\text { rias, óleos, pneus e lixo hospitalar? }\end{array}$ & 23 & 4,0 & 1 & 5 \\
\hline $\begin{array}{l}\text { 24) A cooperativa promove a educação ambiental para } \\
\text { os colaboradores e seus familiares e para a comunidade, } \\
\text { como forma efetiva de reduzir os impactos ambientais? }\end{array}$ & 23 & 3,0 & 1 & 5 \\
\hline $\begin{array}{l}\text { 25) A cooperativa acredita na importância de criar um } \\
\text { plano de ação para monitorar o seu desenvolvimento } \\
\text { e as metas atingidas, bem como analisar a viabilidade } \\
\text { financeira de implementação do modelo de sustentabi- } \\
\text { lidade e a sua continuidade? }\end{array}$ & 23 & 3,0 & 1 & 5 \\
\hline
\end{tabular}

Os dados constantes na Tabela 7 revelam que as questões 22 e 23 têm as maiores médias de percepção dos sujeitos de pesquisa, 4,0, que é definida como "quase sempre". As demais questões referentes a aspectos ambientais têm uma média de 3,0 (21,7\%), que é representada por "às vezes".

Na esfera ambiental, a cooperativa tem se preocupado com o grande número de copos descartáveis que se encontram junto aos bebedouros, jogados nas lixeiras nas dependências da cooperativa tanto por funcionários como por usuários, motivo pelo qual inseriu no dia a dia destes o EcoCopo. Trata-se de um copo ecologicamente correto, feito de material reciclado (papel especial para uso de água), que pode ser utilizado várias vezes e que, quando descartado, não permanece por 400 anos na natureza, diferentemente do copo plástico. Os copos (Figura 4) ficam disponíveis aos usuários e aos funcionários junto aos bebedouros.

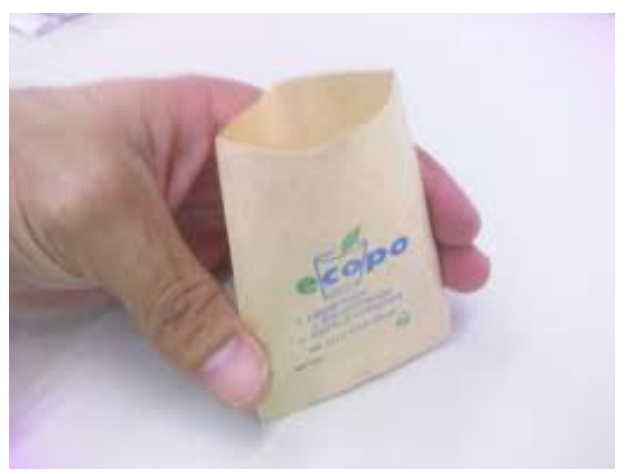

Figura 4. EcoCopo. 
A dimensão ambiental parece ser bastante valorizada pelos gestores da cooperativa, uma vez que a média geral é 3,28. A seguir, na Figura 5, retoma-se a média geral de cada uma das dimensões da sustentabilidade, de acordo com a percepção dos gestores da cooperativa.

Quanto às três dimensões da sustentabilidade (Tabelas 5, 6 e 7), podese destacar que a cooperativa estudada necessita fortificar suas ações principalmente no que tange aos aspectos da dimensão social, que apresentou a média geral mais baixa $(2,55)$. Percebe-se, assim, que existe uma necessidade eminente da cooperativa de participar mais ativamente na comunidade, a fim de levar conhecimentos e informações da es- fera social aos seus cooperados, usuários e gestores. A cooperativa ainda carece de um esforço maior para que os aspectos econômicos possam ser mais bem desenvolvidos, uma vez que essa média se mostrou com potencial para desenvolvimento (média 2,88). A dimensão que apresentou a maior média entre os gestores foi o conjunto que compreende os aspectos da esfera ambiental. Embora se perceba que os gestores estão atentos a essa dimensão de forma mais significativa que as demais, com ações pontuais dentro da cooperativa, como no exemplo da inserção do EcoCopo, compreende-se que ainda há espaço para os gestores da cooperativa ampliarem a sua atuação de forma mais efetiva.

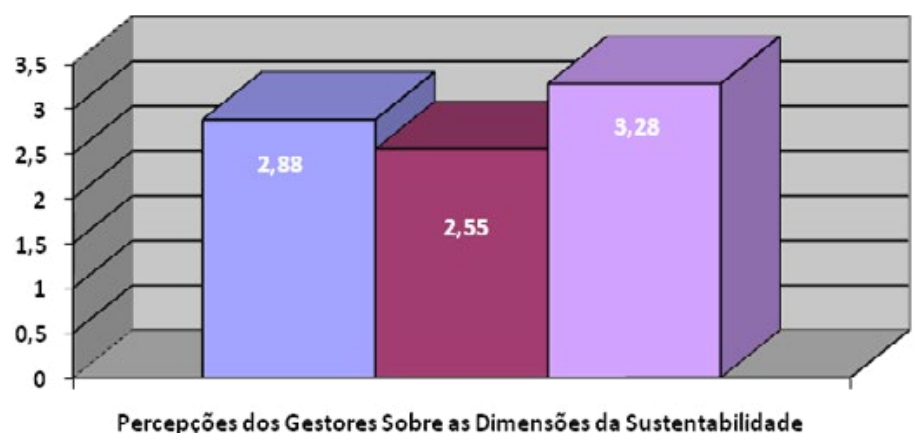

$\square$ Aspectos Económicos
$\square$ Aspectos Sociais
$\square$ Aspectos Ambientais

Figura 5. Médias das três dimensões da sustentabilidade referente às percepções dos gestores

\section{Considerações finais}

Cada vez mais, a sustentabilidade aparece como uma necessidade diante do esgotamento dos recursos naturais. Mais do que modismo, a sustentabilidade é importante para o futuro do planeta e, consequentemente, para cada um que vive nele. Não são poucos os alertas sobre a diminuição da água potável no mundo e sobre o risco do desmatamento, que aumenta a poluição e diminui o ar puro.

O comprometimento das organizações com a questão ambiental vem crescendo desde a inserção de novas tecnologias de produção, informação e comunicação, devido às transformações socioeconômicas ocorridas durante as últimas décadas. Torna-se necessário, nesse contexto, conhecer e reavaliar as atividades econômicas, sociais e ambientais dos diferentes tipos de organizações.

Considerando-se as respostas obtidas dos gestores da cooperativa pesquisada, as características da amostra $\mathrm{e}$ as dimensões que nortearam a investigação, observou-se que os participantes são adultos de meia-idade, o que demonstra que a cooperativa em questão reflete um exemplo do que Porter (1986) identifica como maturidade organizacional. Com relação ao gênero predominante, destaca-se o sexo feminino, o que corrobora com a situação atual do mercado no que tange à crescente participação da mulher conforme dados da ONU (2011), e ressalta-se que elas também estão ocupando cargos de 
chefia, conforme identificado neste estudo. Todos os supervisores possuem ensino superior completo ou especialização, exceto um $(4,3 \%)$ que ainda não concluiu a graduação. Considera-se essa situação positiva, uma vez que a formação acadêmica parece ser valorizada pela cooperativa.

Com relação aos objetivos deste estudo, primeiramente, buscou-se verificar as ações referentes à sustentabilidade aplicadas na cooperativa. Percebese que a cooperativa é uma organização que possui ações voltadas para a sustentabilidade e que os aspectos sociais ainda precisam ser mais desenvolvidos pela organização. Por meio de entrevistas informais com os gestores, levantaram-se algumas melhorias que poderão ser aplicadas com relação às práticas sustentáveis dentro da organização, dentre as quais se destaca a ampliação do material visível aos usuários da cooperativa. Pelos dados desta pesquisa, pode-se constatar que os colaboradores já estão inseridos no contexto sustentável, embora ainda seja preciso inserir também os usuários da cooperativa nessas práticas sustentáveis. Sugere-se, por exemplo, a colocação (na entrada da sede administrativa, na recepção do Hospital e no setor de Medicina Preventiva) de Totens Ecológicos, que são os Coletores Ecológicos com os compartimentos separados, onde as pessoas descartam medicamentos vencidos, pilhas e baterias, seringas e agulhas, dispostos de maneira que não só os colaboradores tragam materiais de casa e ali depositem, mas também os clientes da cooperativa disponham desse serviço. Obviamente que, quando do recolhimento dos materiais ali depositados, terão de ser descartados a uma empresa devidamente credenciada, que dê o destino correto aos produtos. Ressalta-se que essas sugestões podem ser colocadas em prática gradativamente, de acordo com a disponibilidade e aceitação dos gestores da cooperativa. Ressalta-se, também, a importância de a diretoria participar mais das atividades realizadas, visto que é imprescindível que os empresários, executivos e administradores passem a se preocupar com a gestão ambiental no universo corporativo.

No que concerne à questão social, a cooperativa necessita ampliar o esclarecimento sobre práticas sustentáveis (promovendo treinamento e criação de um Comitê para a Sustentabilidade) e a forma de proteção e preservação do meio ambiente, para que os próprios gestores tenham conhecimento para repassar informações e propor melhorias que auxiliem essas práticas. A cooperativa necessita, dessa forma, preocupar-se mais em buscar e disponibilizar informações aos cooperados, colaboradores e usuários, o que pode ocorrer por meio de campanhas, cursos, reuniões e palestras. Essas iniciativas podem promover, cada vez mais, a proximidade com essa comunidade (cooperados, colaboradores e usuários), para assim ter conhecimento de suas necessidades e contribuir para seu bem-estar e sua qualidade de vida.

Sob essa perspectiva, partilha-se do entendimento de que ações que busquem a integração entre essas pessoas, com fortalecimento da cultura familiar, irão refletir na perspectiva social como ponto positivo. Quando a informação, o conhecimento e a capacitação forem desenvolvidos pelos gestores da cooperativa, com a finalidade de diminuir as desigualdades sociais e melhorar as condições de trabalho e renda, apoiando-se na sustentabilidade para garantir o sucesso desse processo e, consequentemente, o desenvolvimento local sustentável de suas comunidades, a qualidade de vida da comunidade aumentará de forma efetiva, pois é a partir dessa união de forças que se consegue promover o desenvolvimento local sustentável.

Por fim, sugere-se a implementação de Indicadores de Responsabilidade Social, pois a sustentabilidade organizacional é uma ferramenta administrativa e estratégica indispensável para que a organização tenha êxito em suas ativi- 
dades. A cooperativa precisa, assim, rever seus atos com relação a esse quesito, pois os gestores não estão conseguindo visualizar a organização como estando comprometida com essa questão. Tal fator pode ser entendido pelo fato de os gestores não procurarem tanto por esses serviços ligados à sustentabilidade e às ações ambientais. Isso representa mais um motivo para a cooperativa se preocupar em promover esse tipo de ação, que vai ao encontro da melhora da realidade encontrada nesta pesquisa.

É possível inferir, ainda, que a cooperativa possui diversas ações inerentes à sustentabilidade, aplicando na prática muitas delas. Porém, de acordo com as respostas dos entrevistados, percebe-se que a dimensão social requer maior atenção da organização, pois representa a dimensão com menor grau de percepção entre os gestores.

Como fatores limitadores da pesquisa, evidencia-se que o estudo em questão contemplou a percepção somente dos gestores e envolveu apenas as três dimensões da sustentabilidade. Outro aspecto se refere ao tipo de análise escolhida estar centrada em aspectos descritivos apenas. Portanto, para futuros estudos, sugere-se a ampliação da pesquisa para os colaboradores e usuários, bem como a realização de pesquisas qualitativas que contemplem outras dimensões da sustentabilidade.

\section{Referências}

ALIGLERI， L.; ALIGLERI， L. A.; KRUGLIANSKAS, I. Gestão socioambiental: responsabilidade e sustentabilidade do negócio. São Paulo: Atlas, 2010.

ALMEIDA, F. Os desafios da sustentabilidade. Rio de Janeiro: Elsevier, 2007.

BACARJI, C. D. Conferência Ethos 2011 debaterá nova economia. Instituto Ethos de empresas e responsa- bilidade social. São Paulo, agosto de 2011. Disponível em: <http://www1. ethos.org.br/EthosWeb/pt/5735/servicos_do_portal/noticias/itens/conferencia_ethos_2011_debatera_nova_economia_.aspx $>$ Acesso em 10.03.2013.

BRASIL. Constituição da República Federativa do Brasil (redação original). Brasília, DF: Senado Federal: Centro Gráfico, 1988.

BRITO, D. Do discurso à prática. Revista Guia Exame - Sustentabilidade. São Paulo. Editora Abril, pág. 25 e 26. Novembro, 2011.

CLARO, P. B. O.; CLARO, D. P.; AMÂNCIO, R. Entendendo o conceito de sustentabilidade nas organizações. Revista de Administração, v. 43, n. 4, p. 289-300, out/dez, 2008.

CUMMINS, R. A.; GULlONE, E. Why we should not use 5-point Likert scales: the case for subjective quality of life measurement. In: SECOND INTERNATIONAL CONFERENCE ON QUALITY OF LIFE IN CITIES, 2000 Singapura, Anais... Singapura, 2000.

DONAIRE, D. Gestão ambiental na empresa. 2. ed. São Paulo: Atlas, 1999.

FENKER, E. A. Estratégias De Sustentabilidade: Novos Rumos? In: XXXVI ENCONTRO DA ANPAD, 2012, Rio de Janeiro, Anais... Rio de Janeiro, RJ: ANPAD, 2012.

GIL, A. C. Como elaborar projetos de pesquisa. 4. ed. São Paulo: Atlas, 2002.

ITACARAMBI, P. A nova geração de indicadores Ethos. São Paulo, agosto de 2013. Disponível em: <http:// www3.ethos.org.br/cedoc/a-nova-geracao-de-indicadores-ethos $>$. Acesso em 12.12.2013.

LEFF, E. Saber ambiental: sustentabilidade, racionalidade, complexidade, poder. Petrópolis, RJ: Vozes, 2001.

MADRUGA, L. R. R. G. A Localização das Publicações e a Identificação de Tópicos Quentes em Sustentabilida- 
de: uma Primeira Aproximação usando o Web Of Science. Revista de Gestão Social e Ambiental, v. 5, n. 2, p. 34-46, maio/ago. 2011.

MAIMON, D. Passaporte verde: gestão ambiental e competitividade. Rio de Janeiro: Qualitymark, 1996.

MALHOTRA, N. K. Pesquisa de Marketing: Uma orientação aplicada. Tradução de Lene Belon Ribeiro, Monica Stefani. 6. ed. Porto Alegre: Bookman, 2012.

MARCONI, M. A.; LAKATOS, E. M. Técnicas de Pesquisa: planejamento e execução de pesquisas, amostragens e técnicas de pesquisas, elaboração, análise e interpretação de dados. 5. ed. São Paulo: Atlas, 2002.

MELO NETO, F. P.; BRENNAND, J. M. Empresas socialmente sustentáveis. Rio de Janeiro: Qualitymark, 2004.

MINISTÉRIO DO TRABALHO E EMPREGO. Relação anual de informações sociais do ministério do trabalho e emprego - RAIS (2012). Disponível em: $<$ http://www.mte.gov.br/imprensa-mercado-de-trabalho-rais-crescimento-mulheres.htm>. Acesso em 05.12.2013.

MINISTÉRIO DO TRABALHO E EMPREGO. Cadastro geral de empregados e desempregados - CAGED (2012). Disponível em: <http://www.mtps.gov. br/imprensa/cresce-a-participacao-da -mulher-no-mercado-de-trabalho.htm $>$. Acesso em 10.06.2013.

MUNCK, L.; BANSI, A. C.; GALLELI, B. Sustentabilidade em Contexto Organizacional: uma análise comparativa de modelos que propõem trajetórias para sua gestão. Revista de Ciências da Administração, v. 18 , n. 44, p. 91$110,2016$.

NASCIMENTO, L. F. O Insustentável Sustentável. In: XXXII ENCONTRO DA ANPAD. 2008, Rio de Janeiro. Anais... Rio de Janeiro, RJ: ANPAD, 2008.
ORGANIZAÇÃO DAS NAÇÕES UNIDAS, ONU. Women's Empowerment Principles. 2011. Disponível em: $<$ http://weprinciples.org/files/attachments/EN_WEPs_2.pdf $>$. Acesso em 10.12.2013.

PORTER, M. Estratégia Competitiva Rio de Janeiro: Campus, 1986.

RICHARDSON, R. J. Pesquisa social: métodos e técnicas. 3. ed. São Paulo. Atlas, 1999.

SACHS, I. Caminhos para o desenvolvimento sustentável. 3 . ed. Rio de Janeiro. Garamond, 2002.

SOUSA, A. A caminho da consciência. HSM Management Sustentabilidade, ed. especial. São Paulo, p. 20-23, jul. 2011.

TACHIZAWA, T. Gestão ambiental e responsabilidade ambiental corporativa: estratégias de negócios focadas na realidade brasileira. 2. ed. revista e ampliada. São Paulo: Atlas, 2004.

TINOCO. J. E. P. Balanço Social e o Relatório da Sustentabilidade. São Paulo: Atlas, p.13. 2010.

TRIVIÑOS, A. N. S. Introdução à pesquisa em ciências sociais: a pesquisa qualitativa em educação. São Paulo: Atlas, 1987.

VERGARA, S. C. Projetos e relatórios de pesquisa em administração. 5 . ed. São Paulo: Atlas, 2004.

WCED - Comissão Mundial sobre Meio Ambiente e Desenvolvimento: Nosso Futuro Comum (1987). Disponível em: $\quad<$ http://www.un-documents.net/ wced-ocf.htm>. Acesso em 12.11.2013. 